\title{
Kemampuan Asimilasi Kolesterol Tiga Strain Lactobacillus acidophilus Dalam Medium Cair Berkolesterol
}

\section{The Ability for Cholesterol Assimilation of Three Lactobacillus acidophilus Strains in} Cholesterol-containing Media

\author{
Widodo $^{1,2^{*}}$, Indratiningsih ${ }^{1}$, Widyantoro ${ }^{1}$, dan Putri Adi Pertiwi ${ }^{1}$ \\ ${ }^{I}$ Fakultas Peternakan, Universitas Gadjah Mada Yogyakarta \\ ${ }^{2}$ Pusat Studi Bioteknologi, Universitas Gadjah Mada Yogyakarta \\ E-mail:widodohs@ugm.ac.id *Penulis untuk korespondensi
}

\begin{abstract}
The objective of this study was to investigate the ability of three Lactobacillus acidophilus strains FNCC 101, FNCC 108, and FNCC 120 in cholesterol assimilation. Cholesterol assimilation was carried out in vitro by growing $L$. acidophilus strains anaerobically at $37^{\circ} \mathrm{C}$ for 24 hours in cholesterol-containing MRS broth added with oxgall at $0.4 \%(\mathrm{w} / \mathrm{v})$. Concentration of cholesterol in the supernatant was measured by spectrofotometry at $550 \mathrm{~nm}$ and the absorbance was converted to cholesterol levels based on the cholesterol standards prepared separately. Data showed that $L$. acidophilus decreased concentration of cholesterol in the supernatant. Without inoculation with $L$. acidophilus, concentration of cholesterol in the supernatant was $1.46 \mu \mathrm{g} / \mathrm{ml}$, while after inoculation with $L$. acidophilus FNCC 120, 108, and 101 were $0.45,0.47$, and 0.52 $\mu \mathrm{g} / \mathrm{ml}$, respectively. The optimum level of oxgall addition in cholesterol assimilation was at $0.4 \%$ (w/v) with cholesterol observed at $0.52 \mathrm{mg} / \mathrm{ml}$ compared to 0.81 and $0.71 \mu \mathrm{g} / \mathrm{ml}$ for oxgal addition at 0.1 and $0.3 \%$, respectively. Cholesterol assimilation was optimum at $37^{\circ} \mathrm{C}$ as this temperature had the lowest cholesterol concentration at $0.52 \mu \mathrm{g} / \mathrm{ml}$. Cholesterol assimilation was increased after the growth reaching the logarithmic phase, and optimum after growing for 15 hours. It is concluded that $L$. acidophilus FNCC 101 has the highest level of cholesterol assimilation, this assimilation is optimum at $37^{\circ} \mathrm{C}$, oxgall addition at $0.4 \%$ and at logarithmic phase of growth.
\end{abstract}

Keywords: Cholesterol assimilation, in vitro, Lactobacillus acidophilus

Abstrak

Tujuan penelitian adalah mengetahui kemampuan asimilasi kolesterol dari tiga strain Lactobacillus acidophilus FNCC 101, FNCC 108, dan FNCC 120. Uji asimilasi kolesterol dilakukan secara in vitro dengan menumbuhkan strain $L$. acidophilus secara anaerobik pada suhu $37^{\circ} \mathrm{C}$ selama 24 jam pada media MRS broth mengandung kolesterol dan oxgall $0,4 \%(\mathrm{w} / \mathrm{v})$. Konsentrasi kolesterol pada supernatan diukur dengan spektrofotometri panjang gelombang 550nm dan absorbansi yang diperoleh dipakai untuk menghitung kadar kolesterol berdasarkan standar kolesterol.Hasil penelitian menunjukkan bahwa $L$. acidophilus menurunkan konsentrasi kolesterol pada supernatan. Tanpa inokulasi $L$. acidophilus, konsentrasi kolesterol pada supernatan adalah $1,46 \mu \mathrm{g} / \mathrm{ml}$, sedangkan setelah inokulasi dengan $L$. acidophilus FNCC 120, 108 dan 101 konsentrasi kolesterol secara berurutan adalah 0,$45 ; 0,47 ;$ dan $0,52 \mu \mathrm{g} / \mathrm{ml}$. Asimilasi kolesterol optimum terjadi pada penambahan oxgall $0,4 \%(\mathrm{w} / \mathrm{v})$ dengan konsentrasi kolesterol $0,52 \mu \mathrm{g} / \mathrm{ml}$ tersisa di supernatan dibandingkan konsentrasi $0,81 \mathrm{dan} 0,71 \mu \mathrm{g} / \mathrm{ml}$ pada penambahan oxgall 0,1 dan $0,3 \%$. Asimilasi kolesterol optimum pada suhu $37^{\circ} \mathrm{C}$ dengan konsentrasi kolesterol supernatan $0,52 \mu \mathrm{g} / \mathrm{ml}$. Asimilasi kolesterol meningkat setelah pertumbuhan mencapai fase logaritmik dan optimum setelah inkubasi 15 jam. Sebagai simpulan, $L$. acidophilus FNCC 101 mempunyai kemampuan asimilasi kolesterol tertinggi, ini dicapai pada suhu pertumbuhan $37^{\circ} \mathrm{C}$, penambahan oxgall $0,4 \%$ dan pada fase pertumbuhan logaritmik.

Kata kunci: Asimilasi kolesterol, in vitro, Lactobacillus acidophilus 